\title{
Aplikasi Sistem VoIP Menggunakan Smartphone pada Jaringan Wireless LAN \\ Oleh :
}

Afrizal Yuhanef, Ramiati

Staf Pengajar Teknik Elektro Politeknik Negeri Padang

\begin{abstract}
Teknologi komunikasi suara sekarang ini telah banyak digunakan diberbagai lapisan masyarakat. Pada jaringan suara di perkantoran atau pemamfataan Sistem komunikasi berbasis LAN, pesawat telepon terhubung dalam jaringan Privat Automated Branch Exchange (PABX). Voice Over Internet Protocol (VoIP) adalah teknologi yang menawarkan telepon melalui jaringan Internet Protocol (IP). Penggunaan jaringan IP memungkinkan penekanan biaya pada sebuah perusahaan karena dalam penggunaanya tidak perlu membangun sebuah infrastruktur baru. Seperti tidak perlu lagi penambahan access telpon rumah/Privat Automated Branch Exchange (PABX).

Penerapan atau implementasi dari rancangan yang telah dibuat, yaitu mulai dari menginstall sistem operasi dilanjutkan dengan konfigurasi, kemudian menginstall 3CX Phone System, 3CXPhone-1.3.4 dan mengkonfigurasikannya. Dilanjutkan dengan konfigurasi Wireless Access Point dan mengintegrasikan client VoIP dengan Voip Server yang dibangun.Wireless Acces Point yang digunakan sebagai media transfer data pada aplikasi sistem jaringan, mampu menjadi penghubung yang digunakan dalam layanan komunikasi suara melalui bantuan server VoIP berbasis Android. User Datagram Protocol (UDP) salah satu protokol yang paling banyak digunakan dalam komunikasi menggunakan VoIP. Teknologi VoIP berbasis Android dapat meminimalisir biaya operasional suatu perusahaan sehingga dapat berkomunikasi tanpa harus mengeluarkan biaya Pulsa berlebih dan biaya Penyewaan perangkat PABX.
\end{abstract}

\section{PENDAHULUAN}

Teknologi komunikasi suara sekarang ini telah banyak digunakan diberbagai lapisan masyarakat dan di lingkungan perkantoran. Diantaranya jaringan telepon kabel (Telkom), telepon genggam dan smartphone untuk bertukar informasi. Pada jaringan perkantoran, pesawat telepon terhubung dalam jaringan Privat Automated Branch Exchange (PABX). Sedangkan pesawat telepon yang menggunakan jasa layanan operator telepon, seperti PT Telkom, maka pesawat telepon terhubung langsung dengan Sentral Telepon Otomat (STO) terdekat.

Biaya implementasi jaringan dan teknologi yang diterapkan untuk terciptanya jaringan telekomunikasi cukuplah mahal, juga letak geografis menentukan besar kecilnya biaya yang harus dikeluarkan. Jaringan yang adapun juga tidak mendukung personal yang bekerja pada jarak jauh atau diluar lokasi kerjanya. Karena pengguna alat komunikasi harus berada di lokasi perangkat yang dipasang.

$\begin{array}{ccrr}\text { Voice Over } & \text { Internet Protocol } \\ \text { (VoIP) } & \text { adalah } & \text { teknologi } & \text { yang }\end{array}$

menawarkan telepon melalui jaringan Internet Protocol (IP). Penggunaan jaringan IP memungkinkan penekanan biaya pada sebuah perusahaan karena dalam penggunaanya tidak perlu membangun sebuah infrastruktur baru. Sesuai dengan perkembangan teknologi, sistem VoIP dapat digunakan untuk komunikasi antar notebook dengan smartphone maupun hardware telepon IP dengan kualitas yang baik. Sekarang sudah banyak aplikasi client VoIP gratis yang beredar di internet berbasiskan android untuk dapat terhubung ke server VoIP.

\section{Rumusan Masalah}

Berdasarkan latar belakang yang telah diuraikan diatas maka didapat perumusan pembahasan yaitu:Bagaimana membangun dan mengkonfigurasi sebuah server VoIP sehingga Android sebagai client dapat berkomunikasi antara satu dengan lainnya dan, bagaimana cara mengetahui Protokol-Protokol yang digunakan saat berkomunikasi dengan VoIP serta, bagaimana membangun 
sebuah Server VoIP pada sebuah perusahaan dengan memanfaatkan Infrastruktur yang telah ada sehingga dapat meminimalisir biaya operasional .

\section{Tujuan dan Manfaat}

Tujuan dan manfaat dari penulisan ini adalah:

1. Dapat membangun server dan client VoIP dengan memanfaatkan jaringan Wireless LAN yang tersedia

2. Dapat menjelaskan penggunaan Port TCP/IP pada saat berkomunikasi menggunakan komunikasi VoIP.

3. Dapat mengimplementasikan Komunikasi VoIP pada sebuah perusahaan yang telah memiliki infrastruktur jaringan sehingga tidak perlu menambah biya langganan jaringan bulanan.

\section{TINJAUAN TEORITIS}

\section{Jaringan Komputer}

Jaringan komputer adalah sebuah kumpulan komputer, printer dan peralatan lainnya yang terhubung. Informasi dan data disalurkan melalui kabel-kabel (wire line) atau tanpa kabel (wireless). Sehingga memungkinkan pengguna jaringan komputer dapat saling bertukar informasi dan data, mencetak pada printer yang sama dan menggunakan hardware/software yang terhubung dalam jaringan. Tiap komputer, printer atau peripheral yang terhubung dalam jaringan disebut node.

Sebuah jaringan komputer dapat memiliki 2 (dua), puluhan, ribuan atau bahkan jutaan node. Sebuah jaringan biasanya terdiri dari 2 (dua) atau lebih komputer yang saling berhubungan antara 1 (satu) dengan yang lain. Juga dapat saling berbagi sumber daya misalnya CDROM, Printer, pertukaran file, atau memungkinkan untuk saling berkomunikasi secara elektronik.
Komputer yang terhubung tersebut, dimungkinkan berhubungan dengan media kabel, saluran telepon, gelombang radio, satelit, atau sinar infra merah[9].

\section{Wireless Fidelity (WiFi)}

Teknologi internet berbasis Wi-Fi dibuat dan dikembangkan sekelompok insinyur Amerika Serikat yang bekerja pada Institute of Electrical and Electronis Engineers (IEEE) berdasarkan standar teknis perangkat bernomor 802.11b, 802.11a dan 802.16. Perangkat Wi-Fi sebenarnya tidak hanya mampu bekerja di jaringan WLAN, tetapi juga di jaringan Wireless Metropolitan Area Network (WMAN).

Karena perangkat dengan standar teknis $802.11 \mathrm{~b}$ diperuntukkan bagi perangkat WLAN yang digunakan di frekuensi 2,4 GHz atau yang lazim disebut frekuensi ISM (Industrial, Scientific and Medical). Sedang untuk perangkat yang berstandar teknis 802.11a dan 802.16 diperuntukkan bagi perangkat WMAN atau juga disebut Wi-Max, yang bekerja di sekitar pita frekuensi $5 \mathrm{GHz}$. . Spesifikasi WiFi.[5].

\section{Komponen Utama Jaringan $\mathbf{W i}-\mathbf{F i}$}

Terdapat empat komponen utama untuk membangun jaringan $W i-F i$, yaitu sebagai berikut:

1. Acces Point adalah Komponen yang berfungsi menerima dan mengirimkan data dari adapter wireless. Access Point mengkonversi sinyal frekuensi radio menjadi sinyal digital atau sebaliknya. Komponen tersebut bertugas seperti sebuah hub/switch pada jaringan internet.

2. Wireless LAN Interfaceadalah peralatan yang dipasang di Desktop/mobile PC, peralatan yang dikembangkan secara massal adalah dalam bentuk Personal Computer Memory Card International Association (PCMCIA) card, PCI card maupun 
melalui port Universal Serial Bus (USB).

3. Mobile/Desktop PC adalah Komponen perangkat akses untuk klien, mobile PC pada umumnya sudah terpasang port Personal Computer Memory Card International Association (PCMCIA).

4. Antena external (optional) adalah Antena external ini digunakan untuk memperkuat daya pancar. Antena dapat dirakit sendiri oleh user. contoh : wajan bolik, antena kaleng,dll.[4]

\section{Topologi Jaringan Wi-Fi}

Secara teori pada jaringan wireless ada dua topologi yang dapat di bentuk. Topologi yang dimaksud yaitu topologi ad-Hoc dan infrastruktur. Berikut ini penjelasan singkatnya:

1. Topologi ad-hoc sama seperti topologi pada jaringan peer-to-peer, yang artinya jaringan yang dibangun hanya menggunakan komponen wireless device tanpa menggunakan access point sebagi penghubung.

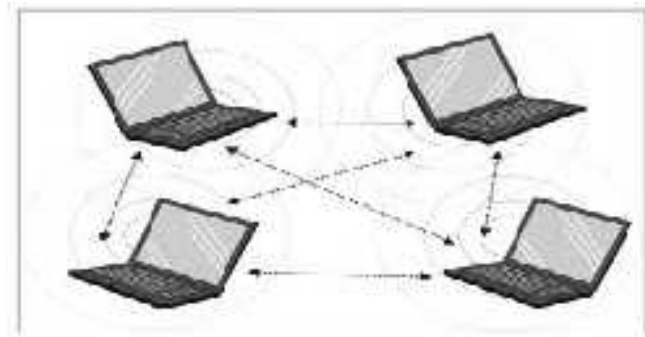

Gambar 1. Ad-hoc.[6]

2. Topologi infrastruktur. Pada topologi ini di butuhkan sebuah access point (AP) sebagai media penghubung. Client sebagai anggota jaringan harus melalui access point terlebih dahulu sebelum dapat berhubungan dengan client lain atau server.

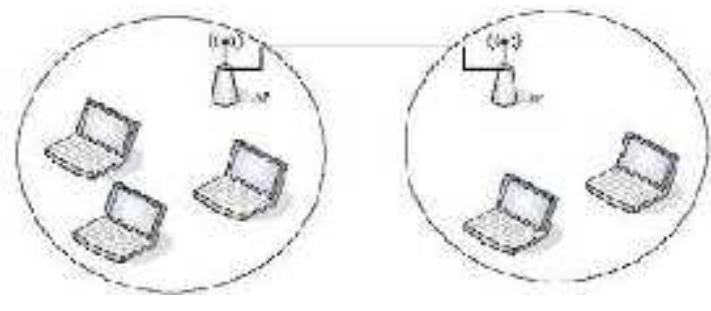

Gambar 2. Infrastruktur

\section{VoIP (Voice Over Internet Protocol)}

Voice over Internet Protocol (juga disebut VoIP, IP Telephony, Internet telephony atau Digital Phone) adalah teknologi yang memungkinkan percakapan suara jarak jauh melalui media internet. Data suara diubah menjadi kode digital dan dialirkan melalui jaringan yang mengirimkan paket-paket data, dan bukan lewat sirkuit analog telepon biasa.

Konsep Dasar VoIP

Teknik dasar Voice over Internet Protokol atau yang biasa dikenal dengan sebutan VoIP adalah teknologi yang memungkinkan kemampuan melakukan percakapan telepon dengan menggunakan jalur komunikasi data pada suatu jaringan (networking). Sehingga teknologi ini memungkinkan komunikasi suara menggunakan jaringan berbasis IP (internet protokol) untuk dijalankan diatas infrastruktur jaringan packet network. Jaringan yang digunakan bisa berupa internet atau intranet. Teknologi ini bekerja dengan jalan mengubah suara menjadi format digital tertentu yang dapat dikirimkan melalui jaringan IP.

Tujuan pengimplementasian VoIP adalah untuk menekan dalam melakukan komunikasi jarak jauh (interlokal/SLI). Penekanan biaya itu dapat dilakukan dengan cara memanfaatkan jaringan data yang sudah ada. Sehingga apabila jika ingin membuat jaringan telekomunikasi VoIP, maka tidak perlu membangun infrastruktur baru yang mengeluarkan biaya yang sangat besar. Jika menggunakan jaringan data yang ada, maka kita melakukan percakapan interlokal maupun internasional hanya dikenakan biaya lokal melalui PSTN.

Internet telephony lebih mengacu pada layanan komunikasi suara (voice), faksimili, dan voice messaging applications. Teknologi ini pada dasarnya mengkonversi sinyal analog (suara) ke format digital dan kemudian dikompres 
atau ditranslasikan ke dalam paket-paket IP yang kemudian ditransmisikan melalui jaringan internet.

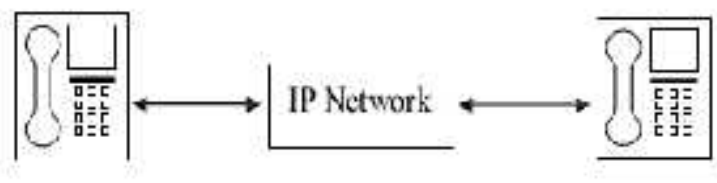

Pembicara 1 Media Pembicara2

Gambar 3. Konsep Dasar VoIP

\section{Kelebihan VoIP}

Adapun kelebihan Voice over Internet Protocol (VoIP), adalah sebagai berikut:

1. Biaya lebih rendah untuk sambungan langsung jarak jauh. Penekanan utama dari VoIP adalah biaya. Jika 2 (dua) lokasi yang terhubung dengan internet/intranet maka biaya percakapan menjadi sangat rendah.

2. Memanfaatkan infrastruktur jaringan data yang sudah ada untuk suara. Berguna bagi perusahaan yang sudah memiliki jaringan. Jika memungkinkan, maka jaringan yang ada bisa dibangun jaringan VoIP dengan mudah. Tidak diperlukan tambahan biaya bulanan untuk penambahan komunikasi suara.

3. Penggunaan bandwidth yang lebih kecil daripada telepon biasa. Dengan majunya teknologi, penggunaan bandwidth untuk voice sekarang ini menjadi sangat kecil.

4. Memungkinkan digabung dengan jaringan telepon lokal yang sudah ada. Dengan adanya gateway bentuk jaringan VoIP bisa disambungkan dengan Privat Automated Branch Exchange (PABX) yang ada di kantor.

\section{Kekurangan VoIP}

Adapun kekurangan Voice over Internet Protocol (VoIP), adalah sebagai berikut:

1. Kualitas suara tidak sejernih Telkom.
Merupakan efek dari kompresi suara dengan bandwidth kecil sehingga akan ada penurunan kualitas suara dibandingkan jaringan PSTN konvensional.

2. Ada jeda dalam berkomunikasi. Proses perubahan data menjadi suara, jeda jaringan, membuat adanya jeda dalam komunikasi dengan menggunakan VoIP.

3. Peralatan relatif mahal. Peralatan VoIP yang menghubungkan antara VoIP dengan IP telephony gateway (PABX) relatif berharga mahal..

4. Jika pemakaian VoIP semakin banyak, maka jaringan data yang ada menjadi penuh jika tidak diatur dengan baik.

\section{Cara Kerja VoIP}

Pengiriman sebuah sinyal ke remote destination dapat dilakukan secara digital, yaitu sebelum dikirim data yang berupa sinyal analog, diubah dulu ke bentuk data digital dengan Analog to Digital Converter (ADC). Kemudian ditransmisikan dan dipulihkan kembali di sisi penerima menjadi data analog dengan digital to analog converter (DAC). Begitu juga dengan VoIP, digitalisasi voice dalam bentuk paket data, dikirimkan dan dipulihkan kembali dalam bentuk voice di sisi penerima. Voice diubah dulu ke dalam format digital karena lebih mudah dikendaikan dalam hal ini dapat dikompresi, dan dapat diubah ke format yang lebih baik.dan data digital lebih tahan terhadap noise dari pada analog.

\section{Komponen VoIP}

Komponen-komponen VoIP terdiri dari user agent, proxy, protokol VoIP, codec dan lain-lain. Komponenkomponen tersebut adalah komponen yang dibutuhkan untuk komunikasi VoIP.

\section{User Agent}




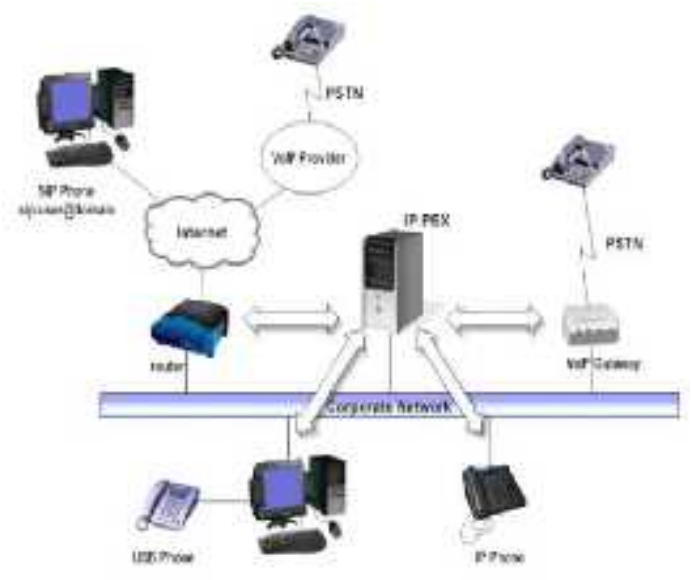

Gambar 4. Topologi VoIP to PSTN menggunakan Accexx PABX

2, Proxy merupakan komponen penengah antar user agent, bertindak sebagai server yang menerima request message dari user agent dan menyampaikan pada user agent lainnya.

2. Protokol VoIP, Protokol-protokol pada teknologi VoIP adalah H.323, Session Initiation Protocol (SIP),Media Gateway Control Protocol (MGCP),IAX.

3. CODEC adalah kependekan dari compression/decompression, mengubah signal audio dan dimampatkan ke dalam bentuk data digital untuk ditransmisikan kemudian dikembalikan lagi ke dalam bentuk signal audio seperti data yang dikirim.

\section{Android}

Android adalah sistem operasi untuk telepon seluler yang berbasis Linux. Android menyediakan platform terbuka bagi para pengembang untuk menciptakan aplikasi mereka sendiri untuk digunakan oleh bermacam peranti bergerak. Awalnya, Google Inc. membeli Android Inc, pendatang baru yang membuat peranti lunak untuk ponsel. Kemudian untuk mengembangkan Android, dibentuklah Open Handset Alliance, konsorsium dari 34 perusahaan peranti keras, peranti lunak, dan telekomunikasi, termasuk Google, HTC, Intel, Motorola, Qualcomm, TMobile, dan Nvidia.

\section{Fitur Android:}

a. Framework aplikasi, memungkinkan daur ulang dan penggantian komponen.

b. Browser terintegrasi berbasis engine Open Source WebKit yang juga digunakan di browser IPhone dan Nokia S60v3.

c. Rancangan handset. Platform disesuaikan dengan kebutuhan Video Graphics Adapter (VGA) yang lebih besar, library grafik 2D dan 3D yang berdasarkan pada spesifikasi OpenGL ES 1.0 serta layout smartphone yang tradisional.

d. Konektivitas. Android mendukung berbagai teknologi konektivitas seperti Global System for Mobile Communications

(GSM)/

Enhanced Data rates for GSM Evolution (EDGE), Code Division Multiple Access (CDMA), Evolution-Data Optimized (EVDO), Universal Mobile Telecommunications System (UMTS),Bluetooth dan Wireless Fidelity (Wi-Fi).

e. Pesan. Android mendukung pengiriman pesan dalam bentuk Short Message Service (SMS) dan Multimedia Messaging Service (MMS).

f. Dukungan Java. Software yang ditulis dalam bahasa Java dapat dikompilasi dan akan dieksekusi pada mesin virtual Dalvik, yang merupakan implementasi dari Virtual Machine (VM) yang dirancang khusus untuk penggunaan perangkat bergerak.

g. Dukungan media. Android mendukung beberapa format audio/video seperti: H.263, H.264 (dalam kontainer 3GP atau MP4), 
MPEG-4 SP, AMR, AMR-WB (dalam kontainer 3GP), AAC, HEAAC (dalam kontainer MP4 atau 3GP), MP3, MIDI, OGG Vorbis, WAV, JPEG, PNG, GIF dan BMP.

h. Dukungan hardware tambahan. Android mendukung penggunaan kamera, layar sentuh, Global Positioning System (GPS), pengukur kecepatan, magnetometer, akselerasi 2D bit blits (dengan orientasi hardware, scaling, konversi format piksel) dan akselerasi grafis 3D.

i. Market. Mirip dengan App Store pada iPhone OS, Android Market adalah sebuah katalog aplikasi yang dapat di-download dan diinstal pada telepon seluler secara online, tanpa menggunakan Personal Computer (PC).

j. Multi-touch. Android memiliki dukungan bawaan untuk multitouch yang tersedia pada handset terbaru seperti HTC Hero

k. Lingkungan pengembangan yang kaya, termasuk emulator, peralatan debugging, dan plugin untuk Eclipse IDE.

\section{Arsitektur Android:}

a. Linux Kernel ,Android bergantung pada Linux Versi 2.6 untuk inti sistem pelayanan seperti keamanan, manajemen memori, proses manajemen, susunan jaringan, dan driver model. Linux kernel menyediakan driver layar, kamera, keypad, kamera, WiFi, memori flash, audio, dan Interprocess Communication (IPC) untuk mengatur aplikasi dan keamanan

b. Library Dasar, Layer kedua di atas kernel terdiri dari library dasar Android. Library ini disusun menggunakan bahasa $\mathrm{C}++$, dicompile sesuai dengan arsitektur pada handphone, dan sudah dimasukkan oleh manufaktur handphone.

c. Android Runtime, Android terdiri dari satu set core libraries yang menyediakan sebagian besar fungsi yang tersedia pada core libraries bahasa pemrograman Java.

d. Application Framework, Pengembang memiliki akses penuh terhadap framework API yang sama yang digunakan oleh aplikasi inti. Application, Android telah menyertakan aplikasi inti seperti email client, SMS, kalender, peta, browser, kontak, dan lain-lain.

\section{METODOLOGI PENELITIAN}

Langkah yang diperlukan untuk merealisasikan system yang direncanakan adalah:

1. Studi Literatur, dilakukan dengan cara mengumpulkan data dan informasi serta mempelajari referensi penunjang baik yang diperoleh dari buku perpustakaan, media cetak, majalah, maupun pencarian bahan dari browsing di internet yang berhubungan. $\mathrm{d}$

2. Konsultasi, melakukan konsultasi dengan orang-orang yang mempunyai pengetahuan dan wawasan terhadap permasalahan yang akan dibahas.

3. Observasi,dilakukan untuk mengetahui dan memperkirakan kebutuhan sarana dan prasarana untuk mendukung sistem yang dibangun.

4. Perancangan VoIP Server menggunakan 3CX Phone System dengan sistem operasi Windows 7. Pada bagian ini akan dilakukan proses desain instalasi dan konfigurasi sistem VoIP server, Wireless Access Point, dan Smartphone Android sebagai Client. Menentukan topologi yang akan digunakan dalam jaringan.

5. Implementasi ,penerapan atau implementasi dari rancangan yang 
telah dibuat, yaitu mulai untuk menginstall sistem operasi dilanjutkan dengan konfigurasi, dilanjutkan dengan konfigurasi Wireless Access Point dan mengintegrasikan client VoIP dengan Voip Server yang dibangun.

6. Pengujian Sistem, pada bagian ini akan dilakukan pengujian sistem menggunakan jaringan wireless dari client menggunakan Access Point yang dibangun.

\section{Perancangan Aplikasi Sistem VoIP Menggunakan Smartphone pada Jaringan Wireless LAN}

Perancangan aplikasi sistem VoIP menggunakan smartphone pada jaringan Wireless LAN dengan sebuah Access Point (AP) sebagai media penghubung. Topologi yang dibangun menggunakan jenis topologi star, dimana beberapa client akan mengakses server VoIP yang dihubungkan oleh access point. Infrastruktur yang mendukung untuk jaringan ini terdiri dari server dan client yang berupa Laptop computer, wireless LAN, smartphone Android dan perangkat lunak pendukung.

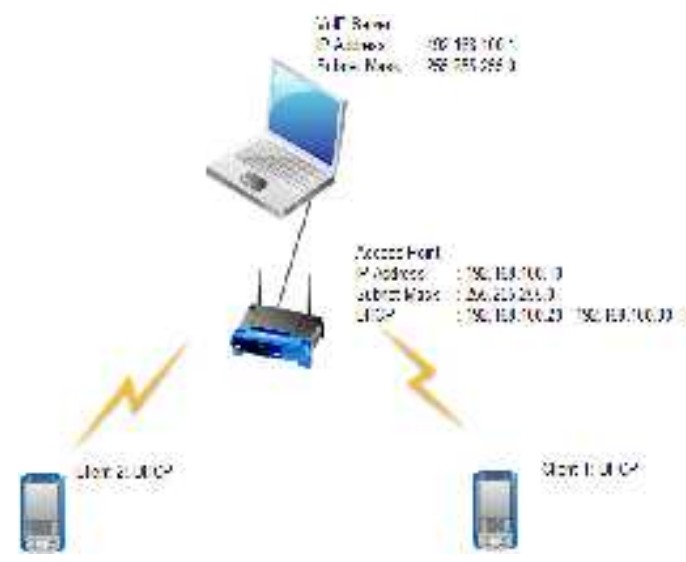

Gambar 5. Konfigurasi WLAN

Dalam perancangan sistem ada beberapa komponen yang dibutuhkan, baik perangkat keras maupun perangkat lunak dalam membangun sistem ini. Pada bagian ini dibahas mengenai infrastruktur yang mendukung komunikasi VoIP, konfigurasi, dan instalasi dari perangkat keras maupun perangkat lunak yang dipergunakan pada jaringan aplikasi sistem VoIP.

Dalam proses implementasi perancangan aplikasi sistem VoIP menggunakan smartphone pada jaringan wireless LAN dengan Acces Point sebagai media penghubungnya. Hal-hal yang akan dibahas meliputi langkah-langkah implementasi dan evaluasi dari hasil perancangan.

Pengkabelan dan Pemasangan Perangkat Jaringan

Dalam implementasi ini diperlukan kabel untuk menghubungkan antar perangkat jaringan, Laptop Computer dihubungkan dengan kabel UTP yang telah terpasang RJ-45 ke perangkat Access Point. Kabel jaringan yang digunakan adalah kabel UTP dengan susunan straight . dan melakukan Konfigurasi pada Access Point. Access Point yang digunakan adalah Micronet SP5601W. Sebelum dimulai pengkonfigurasian, terlebih dahulu dilakukan penyamaan kelas IP address antara access point dengan laptop computer yang digunakan untuk mengkonfigurasinya. Instal perangkat seperti yang disebutkan di atas. Kemudian melakukan penjetingan nAlamat IP yang digunakan

Proses awal konfigurasi diawali dengan tahapan-tahapan konfigurasi seperti diterangkan berikut ini. Pada tahapan pertama dilakukan penetapan kata sandi baru atau password, tahapan kedua adalah penetapan nama identitas network access yang akan terlihat pada saat pencarian jaringan wireless oleh client. Tahapan ketiga adalah penetapan jenis enkripsi keamanan pada saat otentikasi jaringan. Tahapan keempat adalah penetapan IP Address dan range $\mathrm{DHCP}$ jaringan. 


\section{Pembahasan}

Pada Pembuatan aplikasi sistem VoIP menggunakan smartphone pada jaringan Wireless LAN dengan sebuah Access Point (AP) sebagai media penghubung. Topologi yang dibangun menggunakan jenis topologi star, dimana beberapa client akan mengakses server VoIP yang dihubungkan oleh access point. Infrastruktur yang mendukung untuk jaringan ini terdiri dari server dan client yang berupa Laptop computer, wireless LAN, smartphone Android dan perangkat lunak pendukung.

Topologi jaringan

Topologi jaringan VoIP yang akan digunakan adalah sebagai berikut ini, terdiri dari 2 client dan 1 server dengan menggunakan topologi star. Oleh karena itu, topologi jaringan yang akan digunakan ini membutuhkan Access Point sebagai node sentralnya, seperti terlihat pada gambar 6 berikut.

1. Satu Laptop computer digunakan sebagai server VoIP dan dua Smartphone digunakan sebagai client.

2. Pada Laptop computer server VoIP terdapat satu jalur yang dihubung ke sebuah Access Point melalui kabel UTP.

3. Access Point berfungsi sebagai penghubung antara client dengan server dan antara client dengan client lainnya.

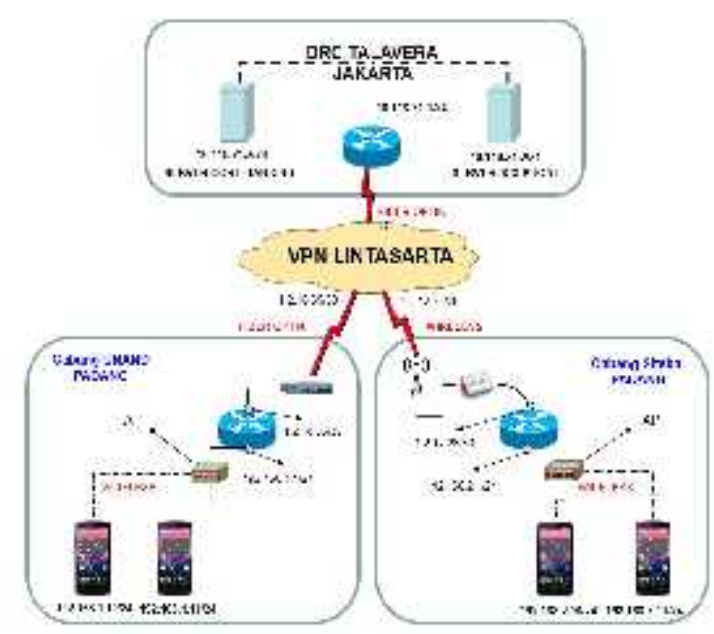

Gambar 6. Topologi Rancangan Jaringan Aplikasi VoIP di Bank Nagari

\section{Komponen Sistem}

Dalam sistem ada beberapa komponen yang dibutuhkan, baik perangkat keras maupun perangkat lunak dalam membangun sistem ini. Pada bagian ini dibahas mengenai infrastruktur yang mendukung komunikasi VoIP, konfigurasi, dan instalasi dari perangkat keras maupun perangkat lunak yang dipergunakan pada jaringan aplikasi sistem VoIP tersebut.

Perangkat Keras dan Perangkat Lunak Pada perangkat keras dan perangkat lunak (hardware / software) yang dibutuhkan untuk aplikasi server VoIP pada jaringan wireless LAN. Perangkat keras dijelaskan pada tabel. Tabel . Perangkat keras

\begin{tabular}{|c|c|c|}
\hline $\begin{array}{c}\text { Perangkat } \\
\text { Keras }\end{array}$ & Jumlah & Spesifikasi \\
\hline $\begin{array}{c}\text { Laptop } \\
\text { Computer } \\
\text { Server VoiP }\end{array}$ & 1 unit & $\begin{array}{c}\text { COMPAQ } \\
\text { Presario CQ43 } \\
\text { Dual Core }\end{array}$ \\
\hline Client & 2 unit & $\begin{aligned} & 1 . \text { HP } \\
& \text { Samsung } \\
& \text { galaxy GT- } \\
& \text { S5660 } \\
& \text { 2. } \text { HP Axioo } \\
& \text { PICOpad_- } \\
& \text { GEA }\end{aligned}$ \\
\hline
\end{tabular}




\begin{tabular}{|c|c|c|}
\hline Access Point & 1 unit & $\begin{array}{c}\text { Micronet } \\
\text { SP5601W }\end{array}$ \\
\hline Kabel UTP & 1 meter & UTP CAT 6 \\
\hline
\end{tabular}

Keterangan:

1. Server meggunakan laptop operasi Windows 7 dan yang berperan sebagai penyedia layanan VoIP di dalamnya adalah 3CXPhoneSystem12.

2. Client menggunakan smartphone dengan Softphone yang terinstal adalah 3CXPhone-1.3.4.apk, dapat di-download pada Appstore atau Google Play secara gratis.

3. Access Point menggunakan wireless MICRONET SP5601W. Proses konfigurasinya dapat dilakukan lewat web browser.

4. Penghubung antara server dengan wireless menggunakan kabel UTP CAT 6 dan konektor RJ 45 pada kedua ujungnya.

\section{Konfigurasi Server VoIP}

a. Server mempunyai alamat IP Address pada Network

- IP Address : 192.168.100.1

- IP Gateway : : 192.168.100.10

- Subnet Mask : 255.255.255.0

b. Server aplikasi sistem VoIP menggunakan 3CX Phone System dengan parameter sebagai berikut:

- IP lokal : 192.168.100.1

- Subnet : 255.255.255.0

- username : admin

- password : admin

- Ekstensi operator:

\section{Konfigurasi Client Smartphone}

Shoftphone yang terinstal pada smartphone sebagai client adalah $3 C X$ Phone. Ada dua Client yang akan digunakan dengan parameternya yang disesuaikan dengan kebutuhan jaringan seperti menentukan nama, passwort dan alamat pada masing-masing client

\section{Konfigurasi Wireless LAN Access Point}

Wireless LAN yang digunakan adalah MICRONET SP5601W yang dapat dikonfigurasi melalui web browser dengan mengetikkan alamat mesin pada bar address-nya yaitu http://192.168.100.1/.

\section{Pembahasan Jaringan}

Dalam pengujian kecepatan dalam tranfer data pada jaringan yang menggunakan protokol TCP/IP dapat diuji dengan menggunakan Software Aplikasi Wireshark. Dalam Penggiriman data menggunakan protokol UDP dan TCP. UDP digunakan pada VoIP karena pada pengiriman audio streaming lebih mementingkan kecepatan agar data dapat cepat sampai ke tujuan tanpa memperhatikan adanya paket yang hilang. UDP merupakan salah satu protokol penting untuk digunakan sebagai header pada pengiriman data selain protokol RTP dan IP. Dalam UDP tidak terdapat mekanisme pengiriman data ulang Pada teknologi VoIP jumlah paket data yang hilang dapat dikurangi dengan cara melakukan pengiriman data melaui private network. Dari data yang didapat protokol yang lebih dominan digunakan adalah protokol UDP. Protokol UTP tidak digunakan dalam pengiriman data suara karena pada komunikasi data VoIP penanganan data yang mengalami keterlambatan lebih penting dari pada penanganan paket yang hilang.

Jadi, dapat disimpulkan bahwasannya Prokotol yang digunakan dalam komunikasi VoIP adalah protokol User Datagram Protocol (UDP).

\section{KESIMPULAN}

Dari hasil implementasi yang telah dilakukan serta uji coba terhadap fungsionalitas serta penampilan dari aplikasi 3CXPhone System (Server) dan 3CXPhone (Client) yang telah dibangun dapat disimpulkan bahwa: 
1. Wireless Acces Point yang digunakan sebagai media transfer data pada aplikasi sistem jaringan, mampu menjadi penghubung yang digunakan dalam layanan komunikasi suara melalui bantuan server VoIP berbasis Android

2. User Datagram Protocol (UDP) adalah salah satu protokol yang paling banyak digunakan dalam komunikasi menggunakan VoIP.

3. Teknologi VoIP berbasis Android dapat meminimalisir biaya operasional suatu perusahaan sehingga dapat berkomunikasi tanpa harus mengeluarkan biaya Pulsa berlebih dan biaya Penyewaan perangkat $\mathrm{PABX}$.

\section{DAFTAR PUSTAKA}

[1] DTC NETCONNECT. 2014. Jenisjenis Topologi. (Online), (http://www. dtcnetconnect.com/AMP/index.php/bl ogs/308-jenis-jenis-topologi jaringanfisik-physical-topology, diakses $6 \mathrm{Mei}$ 2014).

[2] Heriadi, Dodi dan Priyambodo, K. 2005. Jaringan WI-FI, teori dan implementasi. Penerbit ANDI. Yokyakarta. 2005.

[3] Manual 3CX Phone System for Windows Version 12, Version 12.0 Last updated 28th November 2013.

[4] Nugroho, Aries Setio, S.Kom. Membangun Jaringan Komunikasi Berbasis Voip Untuk Koordinasi Pengelolaan Infrastruktur Jardiknas. Modul Pelatihan Teknisi Jardiknas Dan Sim Keuangan Satuan Kerja Di Lingkungan Departemen Pendidikan Nasional 2009.

[5] Purbo, Onno W. Cikal Bakal "Telkom Rakyat": Panduan Lengkap Setting VoIP. 2007

[6] Stallings, William; Jaringan Komputer, Edisi Bahasa Indonesia,
Edisi Pertama; Salemba Teknika. 2002

[7] Sugeng, Winarno, Membangun Telepon berbasis VoIP; Studi Kasus: Implementasi Pada Jaringan RT/RWnet, Bandung: Penerbit Informatika. 2007

[8] Supriyanto, Aji (2006), Analisis Kelemahan Keamanan pada Jaringan Wireless. Jurnal Teknologi Informasi DINAMIK Volume XI, No. 1, Januari $2006: 38-46$

[9] 3CX. 2011. Installing and Configuring 3CX Phone for Android, (Online), (http://www.3cx.com/blog/ex tension-user-manual/install-3cxphone-for-android, diakses, 6 Mei 2014). 